\title{
Equidade nas Decisões Judiciais: Hipótese de cumprimento pelo Estado de sua função social
}

\author{
Carlos Roberto da Silva \\ Mestre em Fundamentos Jurídicos do Direito pela Univer- \\ sidade do Vale do Itajaí - Univali. Doutorando em Ciên- \\ cia Jurídica na mesma instituição. Atualmente é Juiz de \\ Direito da Vara da Fazenda Pública no Fórum da Comarca \\ de Itajaí - SC e professor de Direito Processual Penal \\ no Curso de Graduação em Direito da Univali. crs4766@ \\ gmx.com
}

\begin{abstract}
Resumo
0 presente artigo científico tem como objeto o estudo da equidade como princípio que prevê a adaptação da lei ao caso concreto, por meio da análise dos caracteres pertinentes, dentro do ordenamento jurídico brasileiro, com especial atenção dada aos Juizados Especiais. Faz-se também um estudo sobre o surgimento do Estado, acesso à Justiça e equidade, com uma breve linha do tempo da Grécia Antiga até os dias contemporâneos, apresentando conceitos filosóficos e doutrinários. Contextualizou-se o microssistema dos Juizados Especiais como ferramenta de ampliação do acesso à Justiça e base fomentadora da equidade. Também explicitou-se o conteúdo legal que prevê 0 acesso à Justiça e a aplicação da equidade nas decisões judiciais, bem como a pertinência e relevância desses conceitos ao senso de Justiça. A pesquisa procurou contextualizar que a efetiva aplicação da equidade revela-se indispensável instrumento de aproximação do justo nas decisões judiciais e de cumprimento pelo Estado de sua função social.
\end{abstract}

Palavras-chave: Equidade. Estado. Decisão justa. Função social do Estado.

\section{EQUITY IN JUDGMENTS:}

\section{Hypothesis of compliance by the State of its social function}

\begin{abstract}
This research paper has, as object, the study of the principle of Equity, as it is the adjustment of the law to the real case through the analysis of the relevant characters of the said case, within the Brazilian legal system, with special attention given to the Special Courts. It is also a study on the emergence of the State, the access to Justice and Equity, as well as presents a quick timeline since the Ancient
\end{abstract}


Greece until current times, presenting philosophical and doctrinal concepts. It also contextualized the micro-system of Special Courts as a tool for increasing access to justice and the fomenter basis of Equity. Then, the content, in written law, regarding the access to justice and the application of Equity in Court decisions was shown, as well as the relevance and importance of these concepts to the sense of Justice. The research sought to contextualize that the effective application of Equity proves itself to be an indispensable tool for approximating evenness to judicial decisions and for the State to fulfill its social function.

Keywords: Equity. State. Fair decision. Social function of the State.

\section{Sumário}

Introdução; 1 Estado, Acesso à Justiça e Equidade - Notas Introdutórias; 1.1 Do Surgimento do Estado; 1.2 Do Acesso à Justiça; 1.3 Da Equidade; 20 Microssistema dos Juizados Especiais: Ampliação do Acesso à Justiça e Base Fomentadora da Equidade; 2.1 Evolução Histórica dos Juizados Especiais; 2.20 Advento da Lei o. 9.099/95; 3 A Equidade e o Ordenamento Jurídico Nacional; 3.1 Equidade na Constituição da República Federativa do Brasil de 1988; 3.2 Equidade na Lei de Introdução às Normas do Direito Brasileiro; 3.3 Equidade no Código de Processo Civil; 3.4 Equidade no Código Civil 2002; 3.5 Equidade na Lei no 9.099/95; 3.6 Equidade nas Decisões Judiciais e Cumprimento pelo Estado de sua Função Social; Considerações Finais; 5 Referências. 


\section{INTRODUÇÃO}

Objetiva-se com o presente estudo destacar a importância da categoria equidade e sua aplicação nas decisões judiciais, para que elas se aproximem, tanto quanto possível, de um mecanismo adequado e justo para solução dos conflitos postos à apreciação do Judiciário.

Nesse caminhar enfatiza-se a conceituação da equidade, reforçando sua existência no ordenamento jurídico, com destaque à expressa previsão legal de utilização desse princípio no microssistema dos Juizados Especiais, espaço propício, considerando-se os princípios informadores da informalidade e da simplicidade processuais que regem tal rito processual.

A ideia geral, portanto, é a de que haverá maior efetividade na prestação jurisdicional por parte do Estado - função essa de grande alcance social - se melhor compreendido e aplicado o Princípio da Equidade como ferramenta de produção do Direito, em especial na atuação julgadora, que deve estar preocupada na resolução equitativa das causas postas à análise judicial, que induzem o juiz a um critério de moderação e de igualdade, ainda que em detrimento do Direito objetivo.

Pondera-se que, nas hipóteses em que a decisão tomada, com fundamento na letra fria da lei, não atenda aos anseios da "desejada" justiça, o formalismo exacerbado estará caracterizado e poderá representar uma barreira ao alcance da função social do Estado Constitucional Democrático de Direito.

O procedimento dos Juizados Especiais proporciona, portanto, este espaço de alcance da função social do Estado. Esse desiderato é alcançado mediante a aplicação do instituto da equidade no sentido da liberdade judicial com o fim de criar um procedimento justo, seguindo regras mínimas e princípios legais e constitucionais, a fim de se alcançar a decisão mais adequada para os casos colocados à apreciação do Judiciário. Tal aplica- 
ção equânime alcança uma decisão com o menor dispêndio de tempo e recursos possível, e privilegia a autonomia dos interessados na solução destes conflitos.

Assim compreendida, servirá a equidade como importante ferramenta de alcance da pretendida decisão justa, possibilitando ao Estado a resolução com maior eficácia do problema jurídico evidenciado em uma demanda judicial. Mais bem resolvido o problema jurídico, de forma automática estará o Estado melhor resolvendo o problema social que é, ao mesmo tempo, causa e consequência da questão jurídica formada.

Para tanto, no primeiro tópico serão apresentados os resultados dos estudos efetuados pelo autor acerca das notas introdutórias sobre Estado, acesso à Justiça e equidade. No segundo abordar-se-á o microssistema dos Juizados Especiais como ferramenta de ampliação do acesso à Justiça e base fomentadora da equidade. Por fim, no terceiro tópico será analisada a aplicação da equidade no Ordenamento Jurídico Nacional, perpassando sua previsão na Constituição da República Federativa do Brasil de 1988, Lei de Introdução às Normas do Direito Brasileiro, Código de Processo Civil e Código Civil, bem como a sua utilização como instrumento de aproximação do justo nas decisões judiciais e de cumprimento pelo Estado de sua função social.

A metodologia da pesquisa científica quanto à investigação, tratamento dos dados colhidos e relatos dos resultados adotará o método indutivo. ${ }^{1}$ Nas diversas fases da pesquisa foi utilizada a técnica da pesquisa bibliográfica. $^{2}$

\footnotetext{
1 “[...] pesquisar e identificar as partes de um fenômeno e colecioná-las de modo a ter uma percepção ou conclusão geral [...]”. Pasold, Cesar Luiz. Metodologia da pesquisa jurídica: teoria e prática. 11 ed. Florianópolis: Conceito Editorial; Milleniuum, 2008. p. 86.

2 “Técnica de investigação em livros, repertórios jurisprudenciais e coletâneas legais". Pasold, Cesar Luiz. Metodologia da pesquisa jurídica: teoria e prática. p. 209.
} 


\section{ESTADO, ACESSO À JUSTIÇA E EQUIDADE - Notas Introdutórias}

\subsection{Do Surgimento do Estado}

Anteriormente ao Estado os indivíduos viviam no estado de natureza e tinham de prover sua própria segurança, por não existir a delegação, ao Estado, do direito de punir, como afirma Hobbes, em sua obra Leviatã:

Dessa igualdade de capacidade entre nós resulta a igualdade de esperança quanto ao nosso fim. Essa é a causa pela qual os homens, quando desejam a mesma coisa e não podem desfrutá-la por igual, tornam-se inimigos e, no caminho que conduz ao fim (que é, principalmente, sua sobrevivência e, algumas vezes, apenas seu prazer), tratam de eliminar ou subjugar uns aos outros. Um agressor teme somente o simples poder de outro homem; se alguém semeia, constrói ou possui uma área conveniente, pode estar certo de que chegarão outros que, unindo suas forças, procurarão despojá-lo e privá-lo do fruto de seu trabalho e até de sua vida ou liberdade. O invasor, por seu turno, assumirá o mesmo perigo enfrentado por aquele cuja propriedade invadiu e a quem subjugou. ${ }^{3}$

A Justiça, como senso filosófico, no estado de natureza hobbesiano, não possuía lugar, visto não existir sociedade nem lei. Assim, não havia por que se falar em algo que fosse justo ou injusto, pois não existiam os padrões de comportamento, ética e moral:

Há uma consequiência dessa guerra entre os homens: nada pode ser injusto. As noções de bem e mal, de justiça e injustiça, não encontram lugar nesse procedimento; não há lei onde não há poder comum e, onde não há lei, não há injustiça. As duas principais virtudes na guerra são a força e a fraude. Justiça e injustiça não pertencem às faculdades do

${ }^{3}$ Hobbes, Thomas. Leviatã ou matéria, forma e poder de um estado eclesiástico e civil. Tradução Rosina D’Angina. São Paulo: Martin Claret, 2009. p. 94. (Título original: Leviathan or the Matter, Forme \& Power of a Common-Wealth Ecclesiastical and Civil). 
corpo e do espírito; se assim fosse, existiriam num homem sozinho no mundo, da mesma forma que suas sensações e paixões. Justiça e injustiça só existem entre os homens em sociedade, nunca no isolamento. É natural, também, que não exista propriedade ou domínio, nem distinção entre o que é seu e o que é meu. Apenas pertence a cada homem o que ele é capaz de obter e conservar. O homem, por obra da Natureza, se encontra, pois, nessa miserável condição, embora tenha a possibilidade de superar esse estado contando com suas paixões e sua razão. ${ }^{4}$

Como reiterado por John Locke, todo homem, no estado de natureza, tem o direito de se defender das agressões injustamente sofridas, em benefício de sua integridade e da propriedade de seus bens. Para Locke, ainda, o estado de natureza é apenas o estado em que se encontram as pessoas, livres para fazerem o que quiserem. Aqui, encontram-se todos os indivíduos em um estado de igualdade:

E para que todos os homens sejam impedidos de invadir direitos alheios e de prejudicar uns aos outros, e para que seja observada a lei da natureza, que quer a paz e a conservação de toda a humanidade, a responsabilidade pela execução da lei da natureza é, nesse sentido, depositada nas mãos de cada homem, pelo que cada um tem o direito de punir os transgressores da dita lei em tal grau que impela sua violação. Pois a lei da natureza seria vã, como todas as demais leis que dizem respeito ao homem neste mundo, se não houvesse alguém que tivesse, no estado de natureza, um poder para executar essa lei e, com isso, preservar os inocentes e conter os transgressores. E se qualquer um no estado de natureza pode punir a outrem, por qualquer mal que tenha cometido, todos o podem fazer, pois, nesse estado de perfeita igualdade, no qual naturalmente não existe superioridade ou jurisdição de um sobre outro, aquilo que qualquer um pode fazer em prossecução dessa lei todos devem necessariamente ter o direito de fazer. ${ }^{5}$

${ }^{4}$ Hobbes, Thomas. Leviatã ou matéria, forma e poder de um estado eclesiástico e civil, 2009. p. 97.

${ }^{5}$ Locke, John. Dois tratados sobre o governo. Tradução Julio Fischer. São Paulo: Martins Fontes, 1998, p. 385-386. (Título original: Two Treatises of Government). 
Com o advento do Estado renuncia-se ao poder de autotutela em favor de uma maior segurança e proteção, baseadas em regras gerais de conduta, a fim de viabilizar a vida em Sociedade, o que, segundo Rousseau, torna o homem que vive em Sociedade um "ser inteligente” e, efetivamente, um homem:

Mudança bem notável produz no homem a passagem do estado natural ao civil, substituindo em seu proceder a justiça ao instinto, e dando às suas ações a moralidade de que antes careciam; é só então que a voz do dever sucede ao impulso físico, e o direito ao apetite; o homem que até ali só pusera em si mesmo os olhos vê-se impelido a obrar segundo os outros princípios, e a consultar a razão antes que os afetos. Embora se prive nesse estado de muitas vantagens, que a natureza lhe dera, outros obtém ainda maiores; suas faculdades se exercem e desenvolvem; suas idéias se ampliam, seus sentimentos se enobrecem, sua alma toda inteira a tal ponto se eleva os abusos desta nova condição não o degradassem muitas vezes a uma condição inferior à primeira, muitas vezes a uma inferior à primeira, que se deveria abençoar de contínuo o instante feliz que para sempre o arrancou do estado de natureza, e fez de um animal estúpido e limitado um ser inteligente, um homem. ${ }^{6}$

Assim, o direito de autodefesa é substituído por uma maior segurança, que possibilita a convivência de indivíduos de forma civilizada e organizada, uniformizando o conceito de justiça e mantendo a ordem, a fim de tornar pacífica a interação entre os indivíduos que vivem sob a mesma ordem jurídica.

${ }^{6}$ Rousseau, Jean-Jacques. Do contrato social ou princípios do direito político. Tradução Pietro Nassetti. São Paulo: Martin Claret, 2002. p. 34-35. (Título original: Du contract social; ou, principes du droit politique). 


\subsection{Do Acesso à Justiça}

O acesso à justiça já era preocupação da Sociedade grega, não somente por parte de seus filósofos políticos, mas pelos próprios agentes da justiça, destacando-se características, como:

Em razão do modelo de democracia direta de algumas das cidades gregas, a função de julgar era dos cidadãos, em assembléia, incumbindo unicamente aos magistrados a execução das sentenças. $\mathrm{O}$ acesso era amplo e restrito aos cidadãos. Foi Atenas o berço da assistência judiciária aos pobres, ao nomear anualmente dez advogados para promover a assistência jurídica às pessoas havidas como carentes. ${ }^{7}$

Após, com o Império Romano, para que houvesse um equilíbrio entre as partes litigantes, criou-se a exigência de advogados para as litigâncias, com o objetivo de equilibrar as partes na lide. Novamente, com o intuito de estender o acesso à justiça a todos os cidadãos, caso um indivíduo litigante não tivesse recursos para constituir um advogado, o Estado asseguraria um advogado gratuitamente. ${ }^{8}$

Segundo Cappelletti, o acesso à justiça tem sofrido modificações ao longo da Idade Moderna, trazendo consequências até os dias atuais:

Nos estados liberais "burgueses" dos séculos dezoito e dezenove, os procedimentos adotados para solução dos litígios refletiam a filosofia essencialmente individualista dos direitos, então vigorante. Direito ao acesso à proteção judicial significava essencialmente o direito formal do indivíduo agravado de propor ou contestar uma ação. A teoria era de que, embora o acesso à justiça pudesse ser um "direito natural", os direitos naturais não necessitavam de uma ação do Estado para sua

\footnotetext{
${ }^{7}$ Abreu, Pedro Manoel. Acesso à Justiça e juizados especiais: o desafio histórico da consolidação de uma justiça cidadã no Brasil. 2. ed. rev. e atual. Florianópolis: Conceito Editorial, 2008. p. 45.

${ }^{8}$ Abreu, Pedro Manoel. Acesso à Justiça e juizados especiais: o desafio histórico da consolidação de uma justiça cidadã no Brasil, 2008. p. 46.
} 
proteção. Esses direitos eram considerados anteriores ao Estado; sua preservação exigia apenas que o Estado não permitisse que eles fossem infringidos por outros. O Estado, portanto, permanecia passivo com relação a problemas tais como a aptidão de uma pessoa para reconhecer seus direitos e defendê-los adequadamente, na prática. ${ }^{9}$

No mesmo diapasão, tem-se, de Eros Grau, acerca da efetividade das garantias constitucionais:

A Constituição formal, em especial enquanto concebida como meramente programática - continente de normas que não são normas jurídicas, na medida em que define direitos que não garante, na medida em que esses direitos só assumem eficácia plena quando implementados pelo legislador ordinário ou por ato do Executivo -, consubstancia um instrumento retórico de dominação. ${ }^{10}$

O acesso à Justiça, portanto, que constitui garantia constitucional, deve ser assegurado sob pena de se tornar uma mera garantia formal, não possuindo eficácia no caso concreto.

\subsection{Da Equidade}

Aristóteles, em Ética a Nicômaco, expressa ser a equidade uma forma de justiça, uma vez que as leis, por serem casos hipotéticos e abstratos, devem ser adaptadas ao caso concreto, que possui todo um conjunto de características e peculiaridades, a fim de dizer a justiça da melhor forma:

\footnotetext{
${ }_{9}^{9}$ Abreu, Pedro Manoel. Acesso à Justiça e juizados especiais: o desafio histórico da consolidação de uma justiça cidadã no Brasil, 2008. p. 46.

${ }^{10} \mathrm{Grau}$, Eros Roberto. A ordem econômica na Constituição de 1988. 13. ed. rev. atual. São Paulo: Malheiros, 2008. p. 24.
} 
[...] o eqüitativo, apesar de ser diferente do justo seja ainda assim louvável; com efeito, se os dois são diferentes ou o justo ou o eqüitativo não é bom, e se ambos são bons, eles são a mesma coisa.

[...] o eqüitativo, embora seja melhor que uma simples espécie de justiça, é em si mesmo justo, e não é por ser especificamente diferente da justiça que ele é melhor do que o justo. A justiça e a eqüidade são portanto a mesma coisa, embora a eqüidade seja melhor. O que cria o problema é o fato de o equiitativo ser justo, mas não justo segundo a lei, e sim um corretivo da justiça legal. A razão é que toda lei é de ordem geral, mas não é possível fazer uma afirmação universal que seja correta em relação a certos casos particulares. Nestes casos, então, em que é necessário estabelecer regras gerais, mas não é possível fazê-lo completamente, a lei leva em consideração a maioria dos casos, embora não ignore a possibilidade de falha decorrente desta circunstância.

[...] Com efeito, quando uma situação é indefinida a regra também tem de ser indefinida, como acontece com a régua de chumbo usada pelos construtores em Lesbos; a régua se adapta à forma da pedra e não é rígida, e o decreto se adapta aos fatos de maneira idêntica. ${ }^{11}$

Falcon y Tella, por ocasião de seu estudo sobre Cícero, percebe a existência de duas expressões - aequitas e aequabilitas -, que, apesar de terem relações recíprocas, não possuem o mesmo sentido. A expressão aequabilitas significa igualdade, enquanto aequitas significa equidade. No sentido ciceroniano, bem como em Direito Romano, aequitas e aequabilitas significam a mesma coisa: tratar todos como iguais, garantindo e assegurando os mesmos direitos e a mesma disposição jurisdicional. ${ }^{12}$

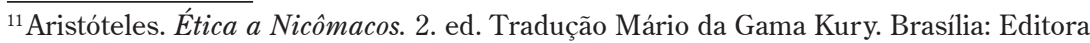

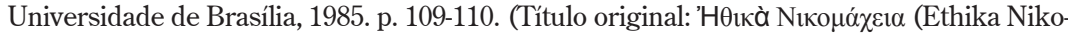
macheia)).

${ }^{12}$ Falcón y Tella, María José. Equity and law. Tradução Peter Muckley. Países Baixos: Martinus Nijhoff Publishers, 2008. p. 33. (Título original: Equidad, Derecho y Justicia). 


\section{O MICROSSISTEMA DOS JUIZADOS ESPECIAIS: Ampliação do Acesso à Justiça e Base Fomentadora da Equidade}

\subsection{Evolução Histórica dos Juizados Especiais}

As bases dos atuais Juizados Especiais, conforme previsto na Lei $\mathrm{n}^{0}$ 9.099/95, encontram berço de origem no Programa Nacional de Desburocratização, bem como nas experiências de magistrados da Bahia, do Paraná e do Rio Grande do Sul, que, no início dos anos 80, instauraram os Conselhos de Conciliação e Arbitramento.

Essas iniciativas tinham como objetivo tornar mais fácil e menos oneroso o ajuizamento de ações de menor complexidade, com o intuito de garantir uma resposta judicial às lides de indivíduos que necessitavam da tutela estatal, mas não possuíam recursos para tanto. Um dos pontos a ser destacado sobre os Conselhos de Conciliação e Arbitramento foi o alto número de conciliações conseguidas por meio de tal instituição.

A resposta do Legislativo ao sucesso até então obtido foi a criação da Lei $\mathrm{n}^{\mathrm{o}} 7.244 / 84$, decretada pelo Congresso Nacional e sancionada pelo presidente da República, que tratava da criação do Juizado Especial de Pequenas Causas, com competência para julgar ações de reduzido valor econômico.

Essa lei permitiu que pessoas mais carentes, financeira e socialmente, ajuizassem ações a fim de obterem a tutela jurisdicional, sem a necessidade do pagamento de custas, taxas ou despesas, facultando-lhes a representação por advogado. 
O novo formato de Justiça, mais próximo da população, foi positivo e rendeu resultados. A Constituição da República Federativa do Brasil de 1988, também conhecida como “Constituição Cidadã”, reconhecendo a importância e eficiência do microssistema processual, consignou expressamente a criação dos Juizados Especiais em seu artigo 98, inciso I:

Art. 98. A União, no Distrito Federal e nos Territórios, e os Estados criarão:

I - juizados especiais, providos por juízes togados, ou togados e leigos, competentes para a conciliação, o julgamento e a execução de causas cíveis de menor complexidade e infrações penais de menor potencial ofensivo, mediante os procedimentos oral e sumaríssimo, permitidos, nas hipóteses previstas em lei, a transação e o julgamento de recursos por turmas de juízes de primeiro grau; ${ }^{13}$

Sobre o tema, colhe-se de Brandão:

A Constituição Federal de 1988 inovou substancialmente em tema de juizados. Primeiro, como já dito, conferiu foro constitucional a esse tipo de jurisdição especial - dantes regulada somente por lei ordinária federal, dando margem a inúmeras discussões acerca da sua constitucionalidade. Num segundo plano, ampliou o conceito de pequenas causas, até então adstrito a um critério meramente valorativo de conteúdo econômico, incluindo, desta feita, as causas cíveis de menor complexidade, agora incorporando na definição da competência um critério qualitativo material, fundado na natureza da lide. A par disso, tornou obrigatória a criação desses juizados pelos Estados, conferindolhes competência concorrente para legislar sobre sua criação, funcionamento e processo. ${ }^{14}$

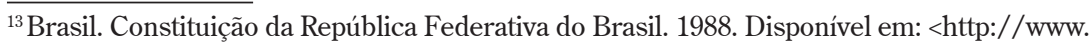
planalto.gov.br/ccivil_03/constituicao/ConstituicaoCompilado.htm>. Acesso em: 23 nov. 2012.

${ }^{14}$ Abreu, Pedro Manoel. Brandão, Paulo de Tarso. Aspectos destacados dos juizados especiais cíveis. In: Juizados especiais cíveis e criminais: aspectos destacados. Florianópolis, Jurídica, 1996. p. 51. 
A instituição dos Juizados Especiais, nos termos preconizados no texto constitucional, só veio a se concretizar em 1995, com o advento da Lei Federal $n^{0} 9.099$.

Como outrora mencionado, o escopo do microssistema processual da Lei $\mathrm{n}^{\circ}$ 9.099/95 foi, além de viabilizar e garantir o efetivo acesso à Justiça, promover a entrega da prestação jurisdicional de modo mais rápido, simplificado e eficaz, utilizando-se, para tanto, dos princípios norteadores previstos em seu artigo $2^{\circ}$, quais sejam, “oralidade, simplicidade, informalidade, economia processual e celeridade, buscando, sempre que possível, a conciliação ou a transação". ${ }^{15}$

No tocante ao acesso à Justiça e à relevância dos Juizados Especiais, infere-se da doutrina de Pedro Manoel Abreu:

$\mathrm{O}$ acesso efetivo à justiça tem sido progressivamente reconhecido como de importância capital entre os novos direitos individuais e sociais. A titularidade de direitos é destituída de sentido na ausência de mecanismos para sua efetiva reivindicação. No dizer de Cappelletti e Garth, o acesso à justiça pode ser encarado como o mais básico dos direitos humanos de um sistema jurídico moderno e igualitário que pretenda garantir e não apenas proclamar os direitos de todos. ${ }^{16}$

E ainda:

No Brasil, a experiência dos juizados de pequenas causas, e mais recentemente dos juizados especiais - com propostas de tutela diferenciada ou de vias alternativas de tutela e modelos de justiça popular, participativa, democrática, e como expressão de justiça coexistencial, pondo em relevo a conciliação e engajando juízes leigos, árbitros e conciliadores

\footnotetext{
$\overline{{ }^{15} \text { Brasil. Lei n⿳o } 9.099}$ de 26 de Setembro de 1995. Dispõe sobre os Juizados Especiais Cíveis e Criminais e dá outras providências. Disponível em: <http://www.planalto.gov.br/ccivil_03/ leis/L9099.htm>. Acesso em: 23 nov. 2012.

${ }^{16}$ Abreu, Pedro Manoel. Acesso à Justiça e Juizados Especiais: o desafio histórico da consolidação de uma justiça cidadã no Brasil, 2008. p. 32.
} 
-, tem servido de contraponto em relação à justiça tradicional, contenciosa, de natureza estritamente jurisdicional, sabidamente saturada, onerosa e tardia. ${ }^{17}$

Depreende-se, portanto, que o legislador brasileiro, por meio de sucessivas legislações - constitucional e infraconstitucional - procurou aparelhar o ordenamento jurídico de tal forma a garantir o efetivo acesso à Justiça em seu sentido mais amplo.

\subsection{O Advento da Lei no 9.099/95}

Embora o acesso à Justiça estivesse conjeturado no rol de garantias previstas no artigo $5^{\circ}$ da Constituição da República Federativa do Brasil de 1988, no Brasil a sociedade, de um modo geral, permanecia afastada do poder Judiciário.

Em muitos casos não havia interesse da maior parte dos ofendidos em procurar a tutela de seus direitos, dado o desconhecimento da lei e diante dos entraves burocráticos de acesso à jurisdição.

Além disso, os custos envolvidos com um processo judicial, aliados ao desembolso com honorários advocatícios, todos a serem arcados pelo proponente da ação, desencorajavam as partes a buscar a tutela de seus interesses e direitos.

Por outro lado, a morosidade na tramitação dos processos, decorrente da falta de recursos e estrutura deficitária, também contribuíam para o afastamento e descrédito da população quanto à atuação do poder Judiciário.

${ }^{17}$ Abreu, Pedro Manoel. Acesso à Justiça e juizados especiais: o desafio histórico da consolidação de uma justiça cidadã no Brasil, 2008. p. 51. 
A fim de equacionar essas dificuldades e garantir o efetivo acesso à Justiça, foram instituídos os Juizados Especiais, cuja criação estava assegurada pela própria Constituição da República Federativa do Brasil de 1988.

Os Juizados Especiais Cíveis e Criminais, criados pela Lei $\mathrm{n}^{0}$ 9.099/95, trouxeram ao ordenamento jurídico brasileiro maior agilidade no processamento de ações, tendo recebido a competência para o processamento e julgamento das causas cíveis de menor complexidade, assim como das infrações penais de menor potencial ofensivo (artigo $3^{\circ}$ da Lei 9.099/95).

O objetivo dos Juizados Especiais, em síntese, é promover a Justiça de modo mais simplificado, célere e eficaz, utilizando-se, para tanto, dos princípios norteadores previstos no artigo $2^{\circ}$ da Lei ${ }^{\circ}$ 9.099/95, quais sejam, “oralidade, simplicidade, informalidade, economia processual e celeridade, buscando, sempre que possível, a conciliação ou a transação”. ${ }^{18}$

Outro atrativo desse microssistema processual é a isenção, em primeiro grau de jurisdição, do pagamento de custas, taxas ou despesas, bem como a possibilidade de dispensa da representação por advogado nas ações de valor não superior a 20 salários-mínimos, fatores que, sem dúvida, facilitam e fomentam o acesso à Justiça, direito fundamental previsto na Constituição da República Federativa do Brasil de 1988.

\footnotetext{
${ }^{18}$ Brasil. Lei no 9.099 de 26 de setembro de 1995. Dispõe sobre os Juizados Especiais Cíveis e Criminais e dá outras providências. Disponível em: <http://www.planalto.gov.br/ccivil_03/ leis/L9099.htm>. Acesso em: 23 nov. 2012.
} 
Como afirma Joel Dias Figueira Júnior, a instituição dos Juizados Especiais representa uma evolução do sistema Judiciário, tornando-se uma ferramenta de importância ímpar no acesso à Justiça por parte das classes da sociedade com menor poder econômico, além de prestar efetivamente a tutela jurisdicional, afastando a "litigiosidade contida" ${ }^{19}$

Desse modo, reconhece-se na criação do microssistema dos Juizados Especiais um significativo avanço no conceito de ampliação do acesso à Justiça no Brasil, à medida que facilita a participação oficial - como destinatários da prestação jurisdicional do Estado - de significativa parcela da sociedade desprovida de recursos.

De igual modo, e indo além da maior abertura de acesso ao serviço Judiciário, afirma-se que seus princípios norteadores, aliados à expressa previsão legal do uso da equidade - como adiante se fundamentará -, criaram um campo fértil à possibilidade do alcance de uma decisão judicial mais justa e, por isso, mais bem compreendida por todos os destinatários.

Nesse sentido, vislumbra-se a hipótese de que possa servir ao cumprimento pelo Estado de sua função social.

\section{A EQUIDADE E O ORDENAMENTO JURÍDICO NACIONAL}

É possível extrair como significado geral, a partir do que modernamente existe em nosso ordenamento jurídico - e não há como negar sua existência, como se verá a seguir - que equidade significa usar do justo e da igualdade para apresentar uma resposta jurisdicional mais apropriada ao desiderato de Justiça em um caso concreto.

${ }^{19}$ Figueira Junior, Joel Dias. Juizados especiais estaduais cíveis e criminais. 4. ed. reform., atual. e ampl. São Paulo: Revista dos Tribunais, 2005. p. 40. 
$\mathrm{Na}$ lei, na qual existem apenas previsões hipotéticas e abstratas, há a necessidade, quando da sua aplicação ao caso concreto, da relativização desta abstração que é instrínseca a sua natureza. Equidade será, pois, nessa linha de pensamento, a adaptação da norma geral ao caso concreto.

Nessa adaptação tem-se o objetivo de tornar a Justiça pertinente ao caso em análise, sendo que as adaptações e aplicações reiteradas das normas explicitarão, na forma como ora se quer explicar o conceito, as diferentes opiniões dos magistrados, ou seja, a jurisprudência.

Da jurisprudência mostra-se a salutar discordância de ideias, prevista por Heller:

As instituições organizadoras do Estado, por perfeitas que sejam, só poderão garantir a observância das formas jurídicas e a segurança jurídica, mas em nenhum caso a juridicidade: a legalidade, porém, não a legitimidade ética dos atos do Estado. Quem unicamente pode assegurar sempre a justiça é a consciência jurídica individual. Mas, com isso, surge no Estado moderno um conflito necessário e insolúvel entre juridicidade e segurança jurídica. Este conflito tem caráter necessário porque em um povo vivo não pode reinar nunca pleno acordo sobre o conteúdo e a aplicação dos princípios jurídicos vigentes. E é insolúvel porque tanto o Estado como o indivíduo se vêem forçados a viver no meio dessa relação de tensão entre direito positivo e consciência jurídica. ${ }^{20}$

Nessa relativização, que é poder e dever de cada magistrado, deve-se levar em consideração o princípio da igualdade e, também, a Justiça. Em igualdade, tem-se que as partes devem ser tratadas de maneira isonômica, com os mesmos direitos e deveres, garantidos e guardados pela lei; em Justiça, tem-se não só a melhor resposta jurisdicional para

${ }^{20}$ Heller, Hermann. Teoria do Estado. Tradução Lycurgo Gomes da Motta. São Paulo: Mestre Jou, 1968. p. 270. (Título original: Staatslehre). 
ambas as partes, determinando esta relação recíproca, mas também o que for mais benéfico à sociedade. Acerca da relativização do direito, tem-se, de Grossi:

A perda da dimensão sapiencial não significa somente subtração do direito a uma classe de indivíduos competentes, os juristas, sejam esse mestres teorizadores ou juízes aplicadores, mas também a perda do seu caráter ôntico, do direito como fisiologia da sociedade, a ser descoberto, lido na realidade cósmica e social e traduzido em regras. ${ }^{21}$

Aristóteles apresenta duas ideias de justiça, uma relativa à justiça de cada indivíduo, que possui ligações com a ética e a moral e outra relativa à lei, que possui ligação com o senso de justiça que somente a lei pode trazer, conforme explana a seguir:

Observamos que, segundo dizem todas as pessoas, a justiça é a disposição da alma graças à qual elas se dispõem a fazer o que é justo, a agir justamente e a desejar o que é justo; de maneira idêntica, diz-se que a injustiça é a disposição da alma graças à qual elas agem injustamente e desejam o que é injusto. Adotemos também esta definição em princípio.

$[\ldots]$

Como as pessoas que infringem as leis parecem injustas e as cumpridoras da lei parecem justas, evidentemente todos os atos conformes à lei são justos em certo sentido; com efeito, os atos estipulados pela arte de legislar são conformes à lei, e dizemos que cada um deles é justo. $[\ldots]$

${ }^{21}$ Grossi, Paulo. Mitologias jurídicas da modernidade. Tradução Arno Dal Ri Júnior. Florianópolis: Fundação Boiteux, 2004, p. 14. (Título original: Mitologie giuridichie della modernitá). 
Com efeito, a justiça é a forma perfeita de excelência moral porque ela é a prática efetiva da excelência moral perfeita. Ela é perfeita porque as pessoas que possuem o sentimento de justiça podem praticá-la não somente em relação a si mesmas como também em relação ao próximo..$^{22}$

Quanto à aplicação da categoria equidade no ordenamento jurídico nacional, as doutrinas de Pablo Stolze Gagliano e Sílvio de Salvo Venosa apresentam, respectivamente, oportunos conceitos:

A eqüidade, na concepção aristotélica, é a "justiça do caso concreto".

Não se trata de um princípio que se oponha à idéia de justiça, mas sim que a completa, tornando-a plena, com a atenuação do rigor da norma, em evidente aplicação do brocardo latino summum jus summa injuria.

$[\ldots]$

Em todos esses casos, é facultado expressamente ao julgador valer-se de seus próprios critérios de justiça, quando for decidir, não estando adstrito às regras ou métodos de interpretação preestabelecidos.

Podemos, inclusive, afirmar que, nesta oportunidade, o julgador deixa de ser juiz - aplicador de regras estatais rígidas - para ser árbitro (que é diferente de arbitrário - ressalte-se), vinculado somente à sua consciência e percepção da justiça, naquele caso concreto, segundo sua própria racionalização do problema.

\section{[...]}

Baseado nesse raciocínio, podemos afirmar que, quando o jurista se defronta com uma lacuna do direito, seja ela axiológica (para os que defendem a plenitude hermética do sistema jurídico), seja ela ontológica (para os que professam o direito como um sistema aberto e dinâmico), deve ser suprida através de um processo de integração da

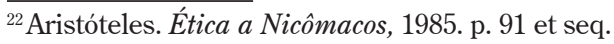


norma, que se pode dar, como já vimos, pela utilização, como meios supletivos, da analogia, do costume, dos princípios gerais de direito e, finalmente, da equiidade.

[...]

Dessa forma, quando houver a contradição entre a norma posta expressamente e a realidade, gerando uma lacuna ou antinomia, pode a eqüidade ser utilizada de forma a encontrar o equilíbrio entre a norma, o fato e o valor, aplicando o direito ao caso concreto. ${ }^{23}$

E, por fim:

Na realidade, o conceito de eqüidade não se afasta do conteúdo do próprio Direito, pois, enquanto o Direito regula a sociedade com normas gerais do justo e equiitativo, a eqüidade procura adaptar essas normas a um caso concreto.

[...]

São frequientes as situações com que se defronta o juiz ao ter de aplicar uma lei, oportunidade em que percebe que, no caso concreto, se afasta da noção do que é justo. $O$ trabalho de aplicação por equiidade é de exatamente aparar as arestas na aplicação da lei para que uma injustiça não seja cometida. A eqüidade é um labor de abrandamento da norma jurídica no caso concreto.

[...]

Na realidade, sintetiza-se que a equiidade se traduz na busca constante e permanente do julgador da melhor interpretação legal e da melhor decisão para o caso concreto. Trata-se, como se vê, de um raciocínio que busca a adequação da norma ao caso concreto. Em momento algum, porém, salvo quando expressamente autorizado pela lei, pode o julgador decidir exclusivamente pelo critério do justo e do equânime, abandonando o texto legal, sob o risco de converter-se em legislador. ${ }^{24}$

${ }^{23}$ Gagliano, Pablo Stolze; Pamplona Filho, Rodolfo. Novo curso de direito civil, volume I: parte geral. 9. ed. rev. atual. e ampl. São Paulo: Saraiva, 2007. p. 22 et seq.

${ }^{24}$ Venosa, Sílvio de Salvo. Direito civil: parte geral. 4. ed. São Paulo: Atlas, 2004. p. 51 et seq. 
Vencida a conceituação da categoria, oportuno discorrer sobre a previsão da equidade em alguns dos diplomas legais vigentes no ordenamento jurídico nacional.

\subsection{Equidade na Constituição da República Federativa do Brasil de 1988}

Na Constituição da República Federativa do Brasil de 1988 a equidade não está expressamente consignada. $\mathrm{O}$ escopo da equidade, contudo, pode ser encontrado, implicitamente, nos princípios constitucionais da dignidade da pessoa humana, da solidariedade social e da igualdade substancial, previstos, respectivamente no artigo $1^{\circ}$, incisos III e IV; artigo $3^{\circ}$, inciso I; artigo 5ㅜ ${ }^{\circ}$ caput, incisos XXXV, XXXVII e LV; artigo 170 e artigo $173, \S 4^{\circ}$, da CRFB/88, como bem observou Carlin. ${ }^{25}$

\subsection{Equidade na Lei de Introdução às Normas do Direito Brasileiro}

A Lei de Introdução às Normas do Direito Brasileiro - DecretoLei $\mathrm{n}^{\mathrm{0}}$ 4.657/42, com alterações introduzidas pela Lei $\mathrm{n}^{\circ}$ 12.376/2010 -, assegura em seu artigo $5^{\circ}$ que "na aplicação da lei, o juiz atenderá aos fins sociais a que ela se dirige e às exigências do bem comum” ${ }^{26}$

\footnotetext{
${ }^{25}$ Carlin, Marcelo. O julgamento por equidade nos juizados especiais cíveis: uma abordagem à luz da convergência entre os Sistemas Jurídicos da Civil Law e da Common Law e do movimento contemporâneo de acesso à Justiça. 2004. 169f. Dissertação (Mestrado em Ciência Jurídica) - Curso de Pós-Graduação Stricto Sensu em Ciência Jurídica, Universidade do Vale do Itajaí, Itajaí, p. 127.

${ }^{26}$ Brasil. Decreto-Lei № 4.657 de 4 de setembro de 1942. Lei de Introdução às normas do Direito Brasileiro. Disponível em: <http://www.planalto.gov.br/ccivil_03/decreto-lei/ Del4657compilado.htm>. Acesso em: 23 nov. 2012.
} 
Assim sendo, o magistrado, na busca da solução do caso sub judice, quando da relativização dos rigores e abstrações do texto legal, pode lançar mão mens legis, voltando-se para os fins sociais e exigências do bem comum a que a lei se dirige.

\subsection{Equidade no Código de Processo Civil}

Dispõe o $§ 3^{\circ}$ do artigo 20 do CPC que:

Art. 20. A sentença condenará o vencido a pagar ao vencedor as despesas que antecipou e os honorários advocatícios. Esta verba honorária será devida, também, nos casos em que o advogado funcionar em causa própria. (...)

$\S 4^{\circ}$ Nas causas de pequeno valor, nas de valor inestimável, naquelas em que não houver condenação ou for vencida a Fazenda Pública, e nas execuções, embargadas ou não, os honorários serão fixados consoante apreciação equiitativa do juiz, atendidas as normas das alíneas a, b e c do parágrafo anterior. ${ }^{27}$

Infere-se, portanto, que ao fixar a verba sucumbencial, o juiz deve, orientando-se pela equidade, pautar o arbitramento dos honorários nos critérios previstos no parágrafo $3^{\circ}$ do referido artigo.

Mais adiante, na forma do artigo 127 do CPC, “o juiz só decidirá por equiidade nos casos previstos em lei” ${ }^{28}$

${ }^{27}$ Brasil. Lei № 5.869 de 11 de janeiro de 1973. Código de Processo Civil. Disponível em: <http://www.planalto.gov.br/ccivil_03/leis/L5869compilada.htm>. Acesso em: 23 nov. 2012.

${ }^{28}$ Brasil. Lei № 5.869 de 11 de janeiro de 1973. Código de Processo Civil. Disponível em: <http://www.planalto.gov.br/ccivil_03/leis/L5869compilada.htm>. Acesso em: 23 nov. 2012. 
Como consequência lógica do princípio da legalidade, a lei só admite o julgamento por equidade nos casos expressamente previstos. A orientação do legislador é no sentido de que o juiz se abstenha de substituir o Direito objetivo por critérios e juízos pessoais de justiça. A vedação não retira do magistrado, todavia, a possibilidade de interpretar a norma legal baseada nos princípios gerais do artigo $5^{\circ}$ da Lei de Introdução às Normas do Direito Brasileiro.

Há que se mencionar, ainda, o teor do artigo 1.109 do CPC, que prevê: “O juiz decidirá o pedido no prazo de 10 (dez) dias; não é, porém, obrigado a observar critério de legalidade estrita, podendo adotar em cada caso a solução que reputar mais conveniente ou oportuna”. ${ }^{29}$

O artigo 1.109, inserido no Título II, que trata dos procedimentos especiais de jurisdição voluntária, assegura que nos procedimentos desta natureza o magistrado não está adstrito ao critério da legalidade estrita, podendo aplicar a equidade ao caso em análise quando assim o julgar oportuno e conveniente para solução da lide.

\subsection{Equidade no Código Civil 2002}

No Código Civil há a previsão expressa da aplicação do Princípio da Equidade em vários dispositivos. A equidade é expressamente prevista, inicialmente, no artigo 413, a saber:

\footnotetext{
$\overline{{ }^{29} \text { Brasil. Lei № } 5.869}$ de 11 de janeiro de 1973. Código de Processo Civil. Disponível em: <http://www.planalto.gov.br/ccivil_03/leis/L5869compilada.htm>. Acesso em: 23 nov. 2012.
} 
Art. 413. A penalidade deve ser reduzida eqüitativamente pelo juiz se a obrigação principal tiver sido cumprida em parte, ou se o montante da penalidade for manifestamente excessivo, tendo-se em vista a natureza e a finalidade do negócio. ${ }^{30}$

No texto do artigo 413, que trata sobre a cláusula penal nos contratos, tem-se que a análise da penalização deve ser feita pelo magistrado com observação ao Princípio da Equidade.

A equidade também é prevista no artigo 479: “A resolução poderá ser evitada, oferecendo-se o réu a modificar eqüitativamente as condições do contrato". ${ }^{31}$ Aqui dá-se a oportunidade ao réu para que utilize a equidade nos casos em que há ação de resolução de contrato por onerosidade excessiva.

Ainda, na prestação de serviços de transporte, expressa o artigo 738:

Art. 738. A pessoa transportada deve sujeitar-se às normas estabelecidas pelo transportador, constantes no bilhete ou afixadas à vista dos usuários, abstendo-se de quaisquer atos que causem incômodo ou prejuízo aos passageiros, danifiquem o veículo, ou dificultem ou impeçam a execução normal do serviço.

Parágrafo único. Se o prejuízo sofrido pela pessoa transportada for atribuível à transgressão de normas e instruções regulamentares, o juiz reduzirá eqüitativamente a indenização, na medida em que a vítima houver concorrido para a ocorrência do dano. ${ }^{32}$

\footnotetext{
${ }^{30}$ Brasil. Lei no 10.406 de 10 de janeiro de 2002. Código Civil. Disponível em: <http://www. planalto.gov.br/ccivil_03/Leis/2002/L10406.htm>. Acesso em: 23 nov. 2012.

${ }^{31}$ Brasil. Lei no 10.406 de 10 de janeiro de 2002. Código Civil. Disponível em: <http://www. planalto.gov.br/ccivil_03/Leis/2002/L10406.htm>. Acesso em: 23 nov. 2012.

${ }^{32}$ Brasil. Lei $\mathrm{n}^{\circ} 10.406$ de 10 de janeiro de 2002. Código Civil. Disponível em: <http://www. planalto.gov.br/ccivil_03/Leis/2002/L10406.htm>. Acesso em: 23 nov. 2012.
} 
No dispositivo supracitado há a figura da culpa concorrente. Nos casos em que a vítima restar prejudicada e que, concomitantemente, haja contribuído para a causa do prejuízo, o juiz deve reduzir a indenização equitativamente.

O próximo dispositivo a citar, expressamente, a utilização da equidade é o artigo 928, que possui a seguinte redação:

Art. 928. O incapaz responde pelos prejuízos que causar, se as pessoas por ele responsáveis não tiverem obrigação de fazê-lo ou não dispuserem de meios suficientes.

Parágrafo único. A indenização prevista neste artigo, que deverá ser eqüitativa, não terá lugar se privar do necessário o incapaz ou as pessoas que dele dependem. ${ }^{33}$

O próprio artigo 928, além de garantir uma indenização equitativa, tem em seu bojo a preocupação com a equidade: expressa que a indenização não poderá existir caso prive o incapaz e/ou as pessoas que dele dependam do necessário para uma sobrevivência digna.

Ademais, o artigo 944, que trata da indenização, traz:

Art. 944. A indenização mede-se pela extensão do dano.

Parágrafo único. Se houver excessiva desproporção entre a gravidade da culpa e o dano, poderá o juiz reduzir, equiitativamente, a indenização. ${ }^{34}$

\footnotetext{
${ }^{33}$ Brasil. Lei $\mathrm{n}^{\mathrm{0}} 10.406$ de 10 de janeiro de 2002. Código Civil. Disponível em: <http://www. planalto.gov.br/ccivil_03/Leis/2002/L10406.htm>. Acesso em: 23 nov. 2012.

${ }^{34}$ Brasil. Lei № 10.406 de 10 de janeiro de 2002. Código Civil. Disponível em: <http://www. planalto.gov.br/ccivil_03/Leis/2002/L10406.htm>. Acesso em: 23 nov. 2012.
} 
Na determinação da indenização do dano deve ser feita a análise equitativa entre a culpa do agente e o dano causado. Com essa análise há a efetiva equidade, haja vista que há uma proporção direta entre os dois fatores.

O próximo dispositivo, por ordem numérica, que trata de equidade, versa sobre a indenização dos crimes de injúria, difamação e calúnia:

Art. 953. A indenização por injúria, difamação ou calúnia consistirá na reparação do dano que delas resulte ao ofendido.

Parágrafo único. Se o ofendido não puder provar prejuízo material, caberá ao juiz fixar, equiitativamente, o valor da indenização, na conformidade das circunstâncias do caso. ${ }^{35}$

$\mathrm{Na}$ indenização pelos crimes contra a honra, caso não haja provas acerca da extensão do dano causado à parte, o juiz deverá fixar o valor, baseado na equidade, tendo em vista o impacto social causado pelo crime.

\subsection{Equidade na Lei no 9.099/95}

Nos Juizados Especiais, o Princípio da Equidade e sua aplicação, além das características pertinentes, estão previstos no artigo $6^{\circ}$, que assegura: "O Juiz adotará em cada caso a decisão que reputar mais justa e equânime, atendendo aos fins sociais da lei e às exigências do bem comum" ${ }^{36}$

\footnotetext{
${ }^{35}$ Brasil. Lei № 10.406 de 10 de janeiro de 2002. Código Civil. Disponível em: <http://www. planalto.gov.br/ccivil_03/Leis/2002/L10406.htm>. Acesso em: 23 nov. 2012.

${ }^{36}$ Brasil. Lei № 9.099 de 26 de Setembro de 1995. Dispõe sobre os Juizados Especiais Cíveis e Criminais e dá outras providências. Disponível em: <http://www.planalto.gov.br/ccivil_03/ leis/L9099.htm>. Acesso em: 23 nov. 2012.
} 
Assim, deve o magistrado pautar sua atuação não só na adequação do caso concreto às hipóteses previstas em lei. Deve ir além, para, utilizando-se dos métodos de interpretação e integração da norma jurídica, resolver a lide de modo que a prestação jurisdicional seja justa e atenda "aos fins sociais da lei e às exigências do bem comum”.

Acerca do assunto, ensina Joel Dias Figueira Júnior que:

Dentro de um contexto axiológico e teleológico, decisão justa não é aquela que simplesmente subsume a norma jurídica ao caso concreto, resolvendo a lide jurídica dentro dos contornos articulados na peça inaugural.

A justiça do julgamento transcende o plano objetivo do sistema nomoempírico prescritivo para adentrar o campo da pacificação social, visto que os conflitos intersubjetivos significam um sintoma patológico nas relações de direito material, pela lesão ou ameaça de lesão ao direito subjetivado. $^{37}$

A atribuição do magistrado é complexa, pois, na qualidade de “agente político de pacificação social," ${ }^{38}$ além do domínio no conhecimento dos fatos litigiosos, bem como do correspondente arcabouço jurídico a ser aplicado, deve ter em mente a necessidade da entrega da prestação jurisdicional de forma justa e equânime.

Nesse sentido, observa Figueira Júnior:

O conflito social, quando levado a juízo, transforma-se em lide, e sua solução, ou melhor, sua mitigação, verifica-se somente com a prolação de uma sentença de mérito. Porém, a sentença de mérito proferida pelo Estado-Juiz compõe a lide judicial, mas não necessariamente o conflito

\footnotetext{
${ }^{37}$ Figueira Junior, Joel Dias. Juizados especiais estaduais cíveis e criminais, 2005. p. 147.

${ }^{38}$ De acordo com Joel Dias Figueira Júnior, o magistrado "não pode aparecer na relação processual como sujeito manipulador do mecanismo da singela subsunção, mas, acima de tudo, como agente político de pacificação social”. Figueira Junior, Joel Dias. Juizados Especiais Estaduais Cíveis e Criminais, 2005. p. 147.
} 
intersubjetivo de interesses. Por isso falamos em mitigação do conflito ou tentativa de solução, posto que as tensões e violências sociais não são redutíveis a estágios de absoluto equilíbrio de pacificação.

Em outras palavras, a aproximação da pacificação social somente vem ser alcançada ou pretensamente alcançada quando a sentença proferida consegue atingir um nível tal de aceitação bilateral (entre autor e réu) e difusa (partes, Estado-Juiz e a coletividade) autorizando-nos a dizer então que, provavelmente, se chegou à verdade hermenêutica pela congruência no exercício do poder de autoridade, liderança e reputação e, por conseguinte, reduzir sensivelmente no mundo jurídico e fatual as tensões e violências apresentadas..$^{39}$

Assim sendo, decisão justa, por sua vez, não é fruto tão somente do preenchimento fático da hipótese abstrata da lei. O ponto de toque reside na interpretação da norma legal, quando, imbuído das diretrizes encerradas no artigo $5^{\circ}$ da Lei de Introdução às Normas do Direito Brasileiro, deve o magistrado trilhar o caminho para a consecução dos "fins sociais da lei e às exigências do bem comum”.

Referidas diretrizes, inclusive, foram reproduzidas pelo legislador quando da elaboração da Lei n. 9.099/95, precisamente no artigo $6^{\circ}$, como outrora citado.

Inclusive a própria interpretação da Lei n. 9.099/95 deve ser sistêmica, na medida em que o funcionamento harmônico dos Juizados Especiais depende da coexistência, quiçá simultânea, dos princípios que norteiam o microssistema.

Dessa forma, de pouca valia se revela o redobrado esforço e dedicação do juiz quando da entrega da decisão "justa e equânime” se todo o encadeamento dos atos processuais foram alheios aos princípios da "oralidade, simplicidade, informalidade, economia processual e celeridade”.

${ }^{39}$ Figueira Junior, Joel Dias. Juizados Especiais Estaduais Cíveis e Criminais, 2005. p. 149. 
De referidos princípios certamente o mais importante, sob a ótica do jurisdicionado, seja o da celeridade. A parte que recorre ao poder Judiciário, na esmagadora maioria das vezes, tem pressa e aguarda ansiosa pela entrega da prestação jurisdicional.

Assim, decisão "justa e equânime” não é somente aquela que faz o temperamento dos rigores da abstração da norma legal ao caso concreto, motivada pelos "fins sociais da lei e às exigências do bem comum". Além de todos estes cuidados, a decisão "justa e equânime” deve ser o desfecho de um processo célere, cujo transcurso do prazo não tenha sido além do suficiente para o exato amadurecimento da causa e para o pleno exercício do contraditório e da ampla defesa.

Aliás, outro não é o sentido da garantia constitucional à "razoável duração do processo e os meios que garantam a celeridade de sua tramitação, ${ }^{40}$ prevista no artigo $5^{\circ}$, inciso LXXVIII, da Constituição da República Federativa do Brasil de 1988.

Nesse sentido, oportunos os esclarecimentos de Joel Dias Figueira Junior:

A Lei 9.099/1995 não está muito preocupada em preconizar a forma em si mesma; sua atenção fundamental dirige-se para a matéria de fundo, ou seja, a concretização, a efetivação do direito do jurisdicionado que acorreu ao Judiciário para fazer valer sua pretensão, com a maior simplicidade e rapidez possível. Em outros termos, tudo isso não passa da incidência do princípio da eqüidade, também preconizado por esta lei (art. $\left.6^{0}\right) .{ }^{41}$

\footnotetext{
${ }^{40}$ Brasil. Constituição (1988). Constituição da República Federativa do Brasil. Disponível em: $<$ http://www.planalto.gov.br/ccivil_03/constituicao/ConstituicaoCompilado.htm>. Acesso em: 23 nov. 2012.

${ }^{41}$ Figueira Junior, Joel Dias. Juizados especiais estaduais cíveis e criminais, 2005. p. 75.
} 
Mediante o emprego da equidade tem-se viabilizada a possibilidade da justa composição do conflito submetido ao exame dos Juizados Especiais. A ideia de decisão justa deve ter efeitos endo e extraprocessuais. Ou seja, além de se revestir dos requisitos legais que lhes são inerentes, a decisão "justa e equânime” deve satisfazer e equacionar os interesses contrapostos das partes litigantes.

\subsection{Equidade nas Decisões Judiciais e Cumprimento pelo Estado de sua Função Social}

Conforme anteriormente mencionado, o Princípio da Equidade está intrinsecamente relacionado com a necessidade da análise e adaptação da decisão ao fim social da lei e à exigência do bem comum. É mister, pois, que tais conceitos recebam a devida atenção e comentários.

A respeito das funções do Estado, especificamente a função social, tem-se de Pasold, pertinente ao tema de igualdade de direitos e acesso à Justiça:

Isto será feito através da dinâmica social que implica a utilização de instrumento estatal em favor da criação e da realização de condições de sensibilidade, racionalidade e acessibilidade - com igualdade de possibilidades - para o homem, frente a alternativas efetivamente existentes nos planos político, social, cultural e econômico. ${ }^{42}$

A função social do Estado, ainda segundo Pasold, é o conjunto de ações e a própria postura que o Estado possui em relação ao cumprimento de políticas que efetivamente têm por objetivo o bem comum. Os interesses sociais devem estar sempre em perspectiva quando o ente estatal toma uma decisão ou propõe ações. Assim:

${ }_{42}$ Pasold, Cesar Luiz. Função social do Estado contemporâneo. Florianópolis: OAB/SC Editora coedição Editora Diploma Legal, 2003. p. 86. 
O Estado Contemporâneo tenha e exerça uma Função Social - a qual implica ações que - por dever para com a Sociedade - o Estado tem a obrigação de executar, respeitando, valorizando e envolvendo o seu sujeito, atendendo o seu objeto e realizando os seus objetivos, sempre com a prevalência do social e privilegiando os Valores fundamentais do Ser Humano. ${ }^{43}$

O bem comum, para Melo, são "fatores propiciados pelo Estado com vistas ao bem-estar coletivo formando o patrimônio social e configurando o objetivo máximo na nação". ${ }^{44}$

Heller, em sua obra Teoria do Estado, discorre sobre as funções de um Estado legitimado e, entre elas, cita a função social:

Uma vez aceito que tais objeções se acham justificadas, há que reconhecer, não obstante, que a questão do fim do Estado não só constitui um problema de importância para a Teoria do Estado, mas o mais fundamental da mesma. Pois embora seja certo que só os homens são capazes de propor conscientemente fins, não o é menos que o Estado, como toda instituição humana, tem uma função objetiva cheia de sentido que nem sempre concorda com os fins subjetivos dos homens que o formam. O Direito Natural do Iluminismo extraíra uma consequiência que induziu a erro, a partir de então, tanto as ciências da natureza como as da cultura, a saber, que a finalidade de um fenômeno deve referir-se à sua criação por uma vontade racionalmente dirigida a um fim. Mas assim como a ciência não pode chegar a admitir a ação de um criador partindo da legalidade imanente do organismo natural, nem da lógica interna da linguagem concluir que foi criado por um espírito do povo (cf. acima, p. 11 e seg.), do mesmo modo não lhe é tampouco permitido explicar a organização estatal por uma ação racionalmente dirigida a um fim, como por exemplo, por um contrato entre homens.

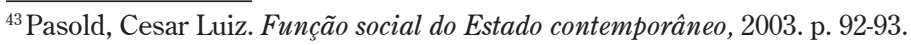

${ }^{44}$ Melo, Osvaldo Ferreira de. Dicionário de Direito Político. Rio de Janeiro: Forense, 1978. In: Pasold, Cesar Luiz. Função social do Estado contemporâneo. Florianópolis: OAB/SC, Editora coedição Editora Diploma Legal, 2003. p. 48. 


\section{$[\ldots]$}

As ações que o Estado exerce, como causa, dentro do todo social determinam-se com a mesma objetividade que as funções que possuem certos órgãos no organismo animal ou vegetal para a nutrição, reprodução ou defesa. O causal e o teleológico não constituem oposições de princípios na compreensão da realidade social (Wundt, Logik, 1919, p. 197 e segs.). Não é possível o Estado sem a atividade, conscientemente dirigida a um fim, de certos homens dentro dele. Os fins estabelecidos por esses homens atuam causalmente sobre outros homens como elementos motivadores das suas vontades. A realidade do Estado, que se deve supor aqui como unidade, consiste em sua ação ou função, a qual, assim como ela, não precisa que seja querida como fim, nem por todos os membros nem mesmo por um só. O Estado existe unicamente nos seus efeitos. "A função é a existência pensada em atividade" (Goethe).

$[\ldots]$

A função do Estado consiste, pois, na organização e ativação autônomas da cooperação social-territorial, fundada na necessidade histórica de um status vivendi comum que harmonize todas as oposições de interesses dentro de uma zona geográfica, a qual, enquanto não exista um Estado mundial, aparece delimitada por outros grupos territoriais de dominação de natureza semelhante. ${ }^{45}$

No ordenamento jurídico brasileiro, nos casos em que a lei nada dispuser sobre um determinado assunto, devem ser observados, especialmente nos Juizados Especiais, dada sua efetiva ligação ao acesso à Justiça e a efetiva prestação de tutela jurisdicional, bem como com a guarda dos direitos, a orientação do artigo $5^{0}$ da Lei de Introdução às Normas do Direito Brasileiro - posteriormente reproduzida no artigo $6^{0}$ da Lei $n$. 9.099/95 -, que assegura que "na aplicação da lei, o juiz atenderá aos fins

${ }^{45}$ Heller, Hermann. Teoria do Estado, 1968. p. 242 et seq. 
sociais a que ela se dirige e às exigências do bem comum” ${ }^{46}$ Perceptível, portanto, é a preocupação do legislador em relação ao fato de que o juiz deve decidir sempre no melhor interesse da sociedade e com equidade.

A discricionariedade do juiz não abre possibilidades para uma criação e aplicação de um direito próprio do magistrado, isso porque deve ser respeitado o princípio da legalidade, que limita o seu poder e o submete a agir em conformidade com a lei, como argumenta Dinamarco:

Constitui segurança para todo o sistema de limitações ao exercício do poder pelo juiz, de deveres deste perante as partes e de oportunidades definidas na lei e postas à disposição delas, para atuação de cada uma no processo segundo seu próprio juízo de conveniência (regras de procedimento, prova, recursos, etc.). A efetiva observância dessa limitações e deveres, mais a oferta dessas oportunidades mediante a racional interpretação e efetivação das regras formais do processo, são inerência da legalidade do Estado-de-direito. ${ }^{47}$

Por fim, tem-se que o magistrado, amparado por uma maior discricionariedade, que lhe permite agir baseado na Justiça real, na equidade e nos interesses sociais, serve-se desses preceitos para prestar a tutela jurisdicional inserido no contexto social, aproximando-se das partes em litígio e tendo uma maior perspectiva em relação ao caso concreto. Esses fatores, aliados à liberdade probatória prevista, notadamente, no artigo 131 do Código de Processo Civil, permitem ao magistrado um maior e melhor olhar sobre cada caso, facilitando a prestação jurisdicional adaptada ao social, que é um poder-dever do magistrado previsto em lei.

\footnotetext{
${ }^{46}$ Brasil. Decreto-Lei № 4.657 de 4 de setembro de 1942. Lei de Introdução às normas do Direito Brasileiro. Disponível em: <http://www.planalto.gov.br/ccivil_03/decreto-lei/ Del4657compilado.htm>. Acesso em: 23 nov. 2012.

${ }^{47}$ Dinamarco, Cândido Rangel; Grinover, Ada Pellegrini. Teoria geral do processo. In: Abreu, Pedro Manoel. Acesso à Justiça e Juizados Especiais: o desafio histórico da consolidação de uma justiça cidadã no Brasil. Florianópolis: Conceito Editorial, 2008. p. 82.
} 
Segundo Pedro Manoel Abreu:

O juiz moderno há de compreender que deve ter participação efetiva no processo. Deve suplantar o mito da neutralidade concebido pelo direito liberal e assumir um papel crítico e orgânico, que a sociedade está a lhe exigir, na perspectiva da democracia. Num compromisso realmente democrático, deve, enfim, ter uma postura ativa, fundada na isonomia substancial, incumbindo-lhe zelar por um processo justo. ${ }^{48}$

Vital, portanto, o emprego da equidade como indispensável instrumento de aproximação do justo nas decisões judiciais e de cumprimento pelo Estado de sua função social.

Por outro lado, não se pode negar a importância cada vez mais crescente e atuante da preocupação dos operadores e pensadores do Direito com essa que é, certamente, a principal função do Estado - cuidar dos interesses maiores da sociedade.

Ora, em um mundo pós-contemporâneo, cujas relações sofrem evidente influência por fatores ligados à globalização e à transnacionalidade, resgatar a importância da função social do Estado poderá significar o resgate do próprio sentido de manutenção do Estado como instituição, pois não se desconhece que as vicissitudes dessa vida globalizada e transnacional colaboram para a perda da identidade nacional das sociedades e para a perda da própria credibilidade do Estado como instituição fundamental. ${ }^{49}$

\footnotetext{
${ }^{48}$ Abreu, Pedro Manoel. Acesso à Justiça e juizados especiais: o desafio histórico da consolidação de uma justiça cidadã no Brasil, 2008. p. 255.

${ }^{49}$ Cruz, Paulo Márcio. Da soberania à transnacionalidade: Democracia, Direito e Estado no século XXI. Itajaí: Univali Editora, 2011. p. 152-154.
} 


\section{CONSIDERAÇÕES FINAIS}

O Princípio da Equidade, nos termos preconizados pelo artigo $5^{\circ}$ do Decreto-Lei n⿳⺈ 4.657/42 - Lei de Introdução às Normas do Direito Brasileiro - revela-se ferramenta essencial para a consecução da decisão justa, que atenda aos fins sociais e às exigências do bem comum.

Como visto, a equidade aplaina os rigores da abstração da norma legal quando da sua transmutação ao plano concreto dos direitos postos em litígio, o que permite que a entrega da prestação jurisdicional seja mais justa e atenda, de fato, aos anseios das partes litigantes, pondo termo à lide.

Dentro de uma perspectiva de efetividade da prestação jurisdicional, decisão justa e equânime é a solução mais adequada ao caso jurídico posto sob a apreciação do poder Judiciário.

De igual forma, atingindo-se a efetividade preconizada pelo instituto da equidade, atingir-se-á, de igual forma, a função social precípua do Estado, que é servir a sociedade.

Na senda dos Juizados Especiais a equidade, preconizada no artigo $6^{0}$ da Lei n. 9.099/95, deve ser interpretada de forma sistêmica com os princípios norteadores do microssistema, sobretudo a celeridade, na medida em que as partes litigantes anseiam pela rápida resposta do poder Judiciário, e informalidade, pois o excesso de formalismo impede, em certos casos, que a decisão judicial seja a mais justa possível.

A atribuição do magistrado é árdua e complexa, pois, atuando como "agente político de pacificação social," ${ }^{50}$ além do domínio no conhecimento dos fatos litigiosos, bem como do correspondente arcabouço jurídico a

\footnotetext{
${ }^{50}$ De acordo com Joel Dias Figueira Júnior, o magistrado "não pode aparecer na relação processual como sujeito manipulador do mecanismo da singela subsunção, mas, acima de tudo, como agente político de pacificação social”. Figueira Junior, Joel Dias. Juizados especiais estaduais cíveis e criminais, 2005. p. 147.
} 
ser aplicado, deve ter em mente a necessidade da entrega da prestação jurisdicional de forma justa e equânine, de modo a atingir os "fins sociais da lei e às exigências do bem comum”.

Pensando-se, portanto, na importância do uso do instituto da equidade, estar-se-á pensando na hipótese de um serviço judiciário de maior qualidade, que atenda aos verdadeiros anseios sociais de justiça - de resolução com justiça dos casos postos à apreciação do poder estatal.

Nesse ritmo, certamente se estará diante da perspectiva de um poder estatal que atenderá ao fim social que se almeja seja resgatado com maior vigor pelo Estado pós-contemporâneo naquilo que se desenha para o devir do século que há pouco teve início.

\section{REFERÊNCIAS}

ABREU, Pedro Manoel. Acesso à Justiça e juizados especiais: O desafio histórico da consolidação de uma justiça cidadã no Brasil. 2. ed. rev. e atual. Florianópolis: Conceito Editorial, 2008.

ABREU, Pedro Manoel; BRANDÃO, Paulo de Tarso. Aspectos destacados dos juizados especiais cíveis. In: Juizados especiais cíveis e criminais: aspectos destacados. Florianópolis: Jurídica, 1996.

ARISTÓTELES. Ética a Nicômacos. Tradução Mário da Gama Kury. 2. ed. Bra-

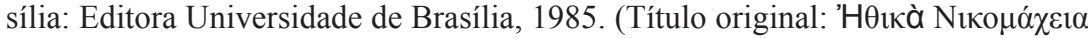
(Ethika Nikomacheia)).

BRASIL. Constituição (1988). Constituição da República Federativa do Brasil. Disponível em: <http://www.planalto.gov.br/ccivil_03/constituicao/ConstituicaoCompilado.htm>. Acesso em: 23 nov. 2012.

BRASIL. Decreto-Lei no 4.657 de 4 de setembro de 1942. Lei de Introdução às normas do Direito Brasileiro. Disponível em: <http://www.planalto.gov.br/ ccivil_03/decreto-lei/Del4657compilado.htm>. Acesso em: 23 nov. 2012. 
BRASIL. Lei № 5.869 de 11 de janeiro de 1973. Código de Processo Civil. Disponível em: <http://www.planalto.gov.br/ccivil_03/leis/L5869compilada.htm>. Acesso em: 23 nov. 2012.

BRASIL. Lei n ${ }^{\circ} 9.099$ de 26 de setembro de 1995. Dispõe sobre os Juizados Especiais Cíveis e Criminais e dá outras providências. Disponível em: <http://www. planalto.gov.br/ccivil_03/leis/L9099.htm>. Acesso em: 23 nov. 2012.

BRASIL. Lei № 10.406 de 10 de janeiro de 2002. Código Civil. Disponível em: <http://www.planalto.gov.br/ccivil_03/Leis/2002/L10406.htm>. Acesso em: 23 nov. 2012.

CARLIN, Marcelo. O julgamento por equidade nos juizados especiais cíveis: uma abordagem à luz da convergência entre os Sistemas Jurídicos da Civil Law e da Common Law e do movimento contemporâneo de acesso à Justiça. 2004. 169f. Dissertação (Mestrado em Ciência Jurídica) - Curso de Pós-Graduação Stricto Sensu em Ciência Jurídica, Universidade do Vale do Itajaí, Itajaí.

CRUZ, Paulo Márcio. Da soberania à transnacionalidade: Democracia, Direito e Estado no século XXI. Itajaí: Univali Editora, 2011.

DINAMARCO, Cândido Rangel; GRINOVER, Ada Pellegrini. Teoria Geral do processo. In: ABREU, Pedro Manoel. Acesso à Justiça e juizados especiais: o desafio histórico da consolidação de uma justiça cidadã no Brasil. Florianópolis: Conceito Editorial, 2008.

FALCÓN Y TELLA, María José. Equity and law. Tradução Peter Muckley. Países Baixos: Martinus Nijhoff Publishers, 2008. (Título original: Equidad, Derecho y Justicia).

FIGUEIRA JUNIOR, Joel Dias. Juizados especiais estaduais cíveis e criminais. 4. ed. reform., atual. e ampl. São Paulo: Revista dos Tribunais, 2005. GAGLIANO, Pablo Stolze; PAMPLONA FILHO, Rodolfo. Novo curso de direito civil. Volume I: parte geral. 9. ed. rev. atual. e ampl. São Paulo: Saraiva, 2007. GRAU, Eros Roberto. A ordem econômica na Constituição de 1988. 13. ed. rev. atual. São Paulo: Malheiros, 2008. 
GROSSI, Paulo. Mitologias jurídicas da modernidade. Tradução Arno Dal Ri Júnior. Florianópolis: Fundação Boiteux, 2004. (Título original: Mitologie giuridichie della modernitá).

HELLER, Hermann. Teoria do Estado. Tradução Lycurgo Gomes da Motta. São Paulo: Mestre Jou, 1968. (Título original: Staatslehre).

HOBBES, Thomas. Leviatã ou matéria, forma e poder de um estado eclesiástico e civil. Tradução Rosina D’Angina. São Paulo: Martin Claret, 2009. (Título original: Leviathan or the Matter, Forme \& Power of a Common-Wealth Ecclesiastical and Civil).

LOCKE, John. Dois tratados sobre o governo. Tradução Julio Fischer. São Paulo: Martins Fontes, 1998. (Título original: Two Treatises of Government).

MELO, Osvaldo Ferreira de. Dicionário de Direito Político. Rio de Janeiro: Forense, 1978. In: PASOLD, Cesar Luiz. Função social do Estado contemporâneo. Florianópolis: OAB/SC Editora coedição Editora Diploma Legal, 2003.

PASOLD, Cesar Luiz. Função social do Estado contemporâneo. Florianópolis: OAB/SC Editora coedição Editora Diploma Legal, 2003.

PASOLD, Cesar Luiz. Metodologia da pesquisa jurídica: teoria e prática. 11. ed. Florianópolis: Conceito Editorial; Milleniuum, 2008.

ROUSSEAU, Jean-Jacques. Do contrato social ou princípios do direito político. Tradução Pietro Nassetti. São Paulo: Martin Claret, 2002. (Título original: Du contract social; ou, principes du droit politique).

VENOSA, Sílvio de Salvo. Direito civil: parte geral. 4. ed. São Paulo: Atlas, 2004 .

Recebido em: 13/5/2013

Aceito em: 4/8/2013 